\title{
The Search for the 'View of the Totality': from the First Panoramic Landscapes to Virtual Reality
}

\author{
José Antonio Franco Taboada
}

\section{Abstract}

The $360^{\circ}$ panorama is studied as a new form of representation that emerged in the I8th century, which anticipated photography and, as the latter evolved, used it to obtain increasingly reliable representations of reality, even incorporating movement and sound. Nevertheless, the invention of the cinematograph in the late 19th century marked the beginning of the end of the popularity of this new form of representation, which, however, continued to be produced punctually, above all to represent historical events, such as the battle of Gettysburg, or simply for an artistic purpose. The techniques and even the mechanisms, including photography, used to make them and the architecture that housed them are also analyzed.

Finally, as the culmination of two centuries of evolution, virtual reality is discussed, through which, although it has not yet been extensively consolidated, we can return to the point of view of a circular or spherical landscape. Based on these new digital panoramas, we consider how to obtain perspectives with different 'virtual objectives' with which, in a kind of 'reverse graphic engineering, we would return to the origins of those first images of the late 18 th and early 19 th centuries, as a combination of numerous previews [I].

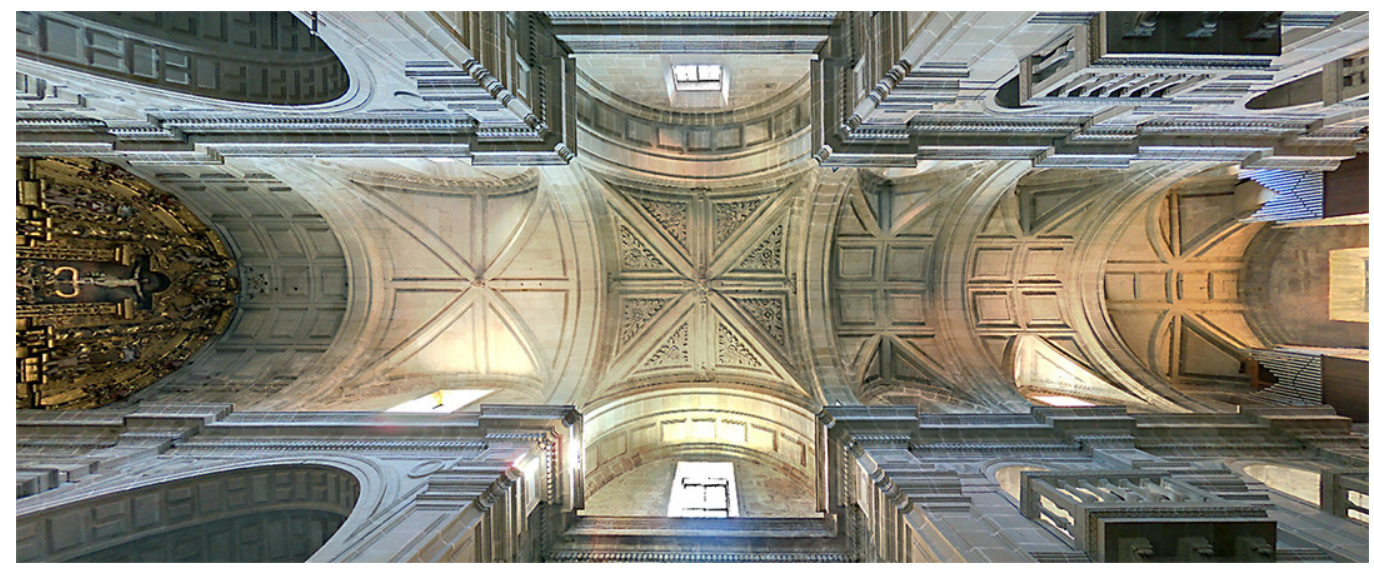


Fig. I. Albrecht Dürer (ca. | $495-1500)$ Tal bei Kalchreuth Kupferstichkabinett der Staatlichen Museen zu Berlin. Retrieved from htrs:/lupload. wikimedia.org/wikipedia/ commons/c/cel. cht D\%C3\%BCrer\%2C Tal_bei_Kalchreuth.jpg

Fig. 2. Zhao Mengfu (1302). Water Village. Th Palace Museum, Beijing Retrieved from https:/ www.comuseum.com/ product/zhao-mengfuwater-village/.

\section{Concept and background}

The concept of panorama is relatively modern. Specifically, the original word was English and was created by Robert Barker by combining the Greek terms 'pan' ('totality') and 'horama' ('view') around 1787. It immediately became popular, as we will see later, and above all its use was extended as an adjective applied to any image -generally of landscapes and/or architectures-, made with a wide visual field, not necessarily of $180^{\circ}$ or $360^{\circ}$.

If we look at the definition of virtual reality, we will see that it is something like "images created by a computer that appear to surround the person looking at them and seem almost real" [2]. If we ignore for a moment the medium used for their creation, what remains is a combination of images that when joined together generate the illusion of spatial depth, faithfully imitating reality. As will be shown later, this is nothing new, since the search for that 'ideal' or perfect representation of reality has accompanied artists since man has been man. The only things that have changed are the means and techniques available to them.

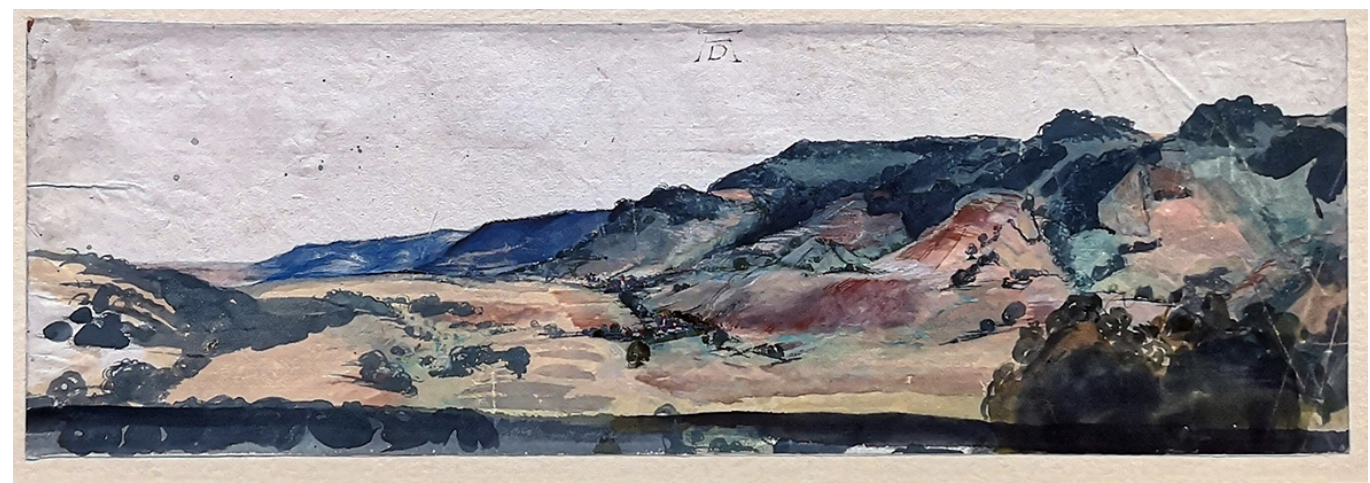

Traditionally, the most immediate antecedents of the panorama are usually situated within Renaissance drawing and painting, when the artist wanted to represent fundamentally a landscape or an architecture. At first, landscapes complemented other images, such as perhaps the most famous, the Mona Lisa. But possibly the firstWestern painter of landscapes and simultaneously of what we today call generically panoramas was Albrecht Dürer, with his Tal bei Kalchreuth (Valley near Kalchreuth) from the end of the I5th century, made in the course of a study trip to Italy. In this painting, the tiny village that appears in the center of the composition does not manage to be -if we are able to see it- enough justification for its creation, which thus becomes the first really non-architectural landscape in Western painting (fig. I). This is in spite of the fact that the one known as Arno Landscape by Leonardo da Vinci is dated 1473, since as Frank Zöllner maintains, although it is considered the first pure landscape drawing of the Renaissance, it is rather related to the imaginary landscapes of Leonardo and his predecessors [Zöllner 2003, p. 5 I 0].

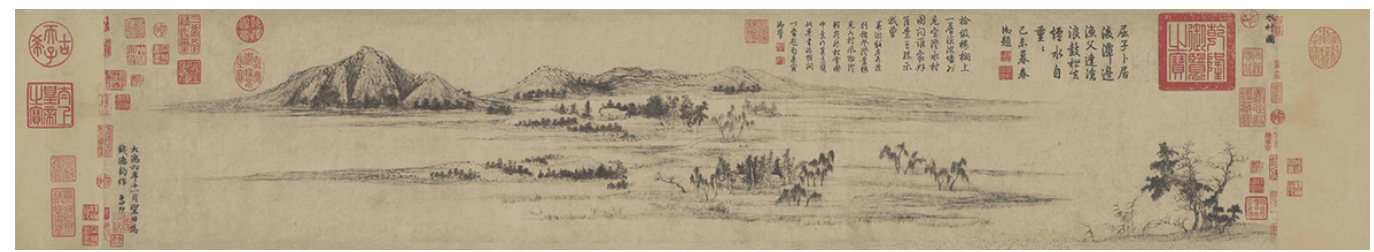

Regardless of who is credited in the West with being the creator of that first pure landscape, there are many much earlier examples in the East, and more specifically in China, of artists who developed harmonious landscapes where architecture was essentially an indicator of scale. Such is the case of the great traveler Fan Kuan, active in the I Oth and early I Ith centuries, who "came to realize that if he really wanted to portray the land, he had to take Nature as his teacher rather than other artists or their works" [3]. This approach was masterfully 
reflected in his work Travelers Among Mountains and Streams [4]. Zhao Mengfu (I 254- I 322), author of Water Village, whose $24.9 \times 120 \mathrm{~cm}$ are observed by manual movement, also stands out (fig. 2). Moreover, somehow, these landscapes made in paper rolls anticipated the moving panoramas that would triumph in the 19th century after the success of the $360^{\circ}$ panoramas that Robert Barker had invented.

\section{Visual fragmentation and spatial construction}

Returning to European painting and already in the 17th century, we find a paradigm shift that Francesca Fatta, regarding Bibiena and Canaletto, synthesizes as follows:

"A fundamental tendency of science, in XVII century, was the research of measurement and observation by means the analysis and the de-constructionism. The visual method, because its own complexion, produces an uniform, incessant and connected space, but the intense visual effort brings to the fragmentation of images, it seems that sight has the specific power to distinguish or catch single space's views in few moments" [Fatta 2016, p. 48]. This new approach was quickly extrapolated to the visual arts, since the fragmentation of the object of study greatly facilitates the apprehension of that enormous continuum that is space. Nathan Knobler has observed that Canaletto's work The Square of Saint Mark's and the Piazzetta, Venice (fig. 3) seems to deny the existence of a single plane in the painting, as had been the norm until then in Renaissance painting. He highlights an aspect of this painting that I believe is a true conceptual antecedent to future panoramas: "It is as thought the artist wished to eliminate the front surface of the painting and make the viewer believe that an actual three-dimensional space existed behind the frame" [Knobler 1980, p. 124].

If we look closely at the painting, we will notice that the part to the left of the campanile is a central linear perspective while the part to the right is an oblique one. The façade of the same that divides both views does not belong to either of the two perspectives; it is a compromise between both. If we go to Google Earth and place Street View just at the northern corner of the Piazza we can see that the view is impossible and that we need to divide it in two, that is, look at the Piazzetta first and then at the Piazza (or vice versa). Of course, this is clear empirical proof that Canaletto could have previously made two separate views using the camera obscura.

Fig. 3. Canaletto (ca. 1731). The Square of Saint Mark's and the Piazzetta, Venice. Wadsworth Atheneum Museum of Art, Hartford. http://argus.wadsworthatheneum.org.

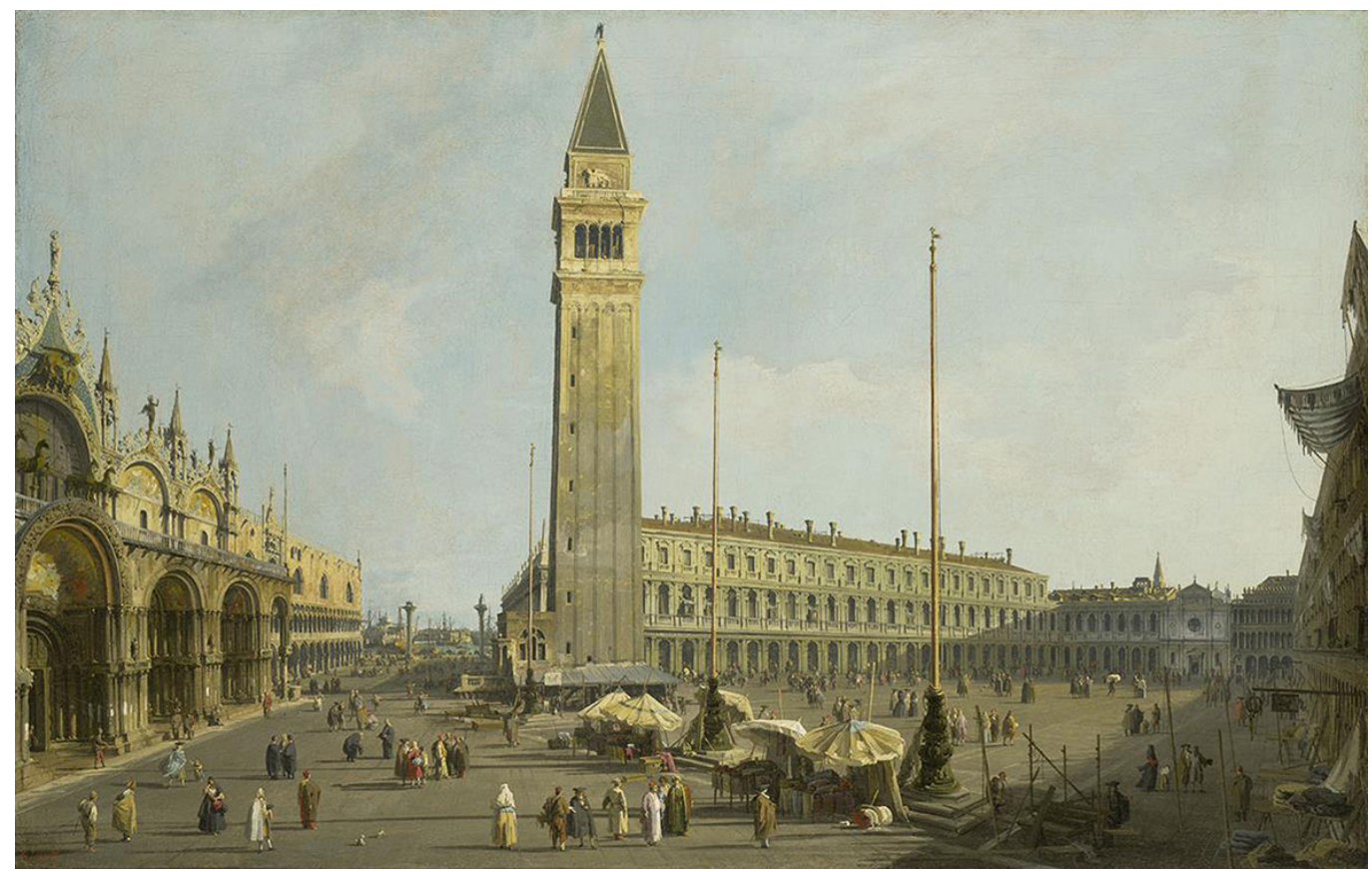


Fifty years later, the Irish artist Robert Barker (1739-1806), who, as noted above, coined the term panorama, also devised an ingenious mechanical system to realize it, the first being a semicircular view of Edinburgh from Calton Hill in 1787. The Art Journal described the technique as he explained it to his skeptical daughter: "but her father said he thought it was to be accomplished by means of a square frame fixed at one spot on the hill: he would draw the scene presented within that frame, and then, shifting the frame to the left or right, he would draw the adjoining part of the landscape; and so going round the top of the hill, he would obtain the view on all sides: and the several drawings being fixed together, and placed in a circle, the whole view might be seen from the interior of the circle, as from the summit of the hill" [Corner I857, p. 46].

If by means of two skillfully joined perspectives Canaletto achieved a very wide view of the whole of San Marcos, of about $180^{\circ}$, Barker took the idea to the limit by making a $360^{\circ}$ view using multiple fragments. Although some of his illustrious contemporaries, such as Sir Joshua Reynolds [5], considered the system impractical, he did not lose heart until he had finished the complete circular view of Edinburgh and, later, of London, Portsmouth, Brighton and even Malta, Gibraltar and Paris, which he exhibited in rooms with cylindrical walls (fig. 4). This activity earned him an entry in the Dictionary of Irish Artists, which described him as follows: "He possessed much inventive talent and devised a mechanical system of perspective which he taught. The view from Calton Hill first suggested the idea of a panorama; and in 1787, assisted by his son Henry then about twelve years of age, he made drawings of a half-circle view from the hill, and after surmounting many difficulties completed his picture in water-colour and took it to London" [Strickland 1913, p. 23].

The success of his invention was such that it quickly spread throughout the world. In France, for example, the most important painter of panoramas, also known as cycloramas, was Pierre Prévost (1764- | 823), who participated in the first French creation of this type, exhibited in 1799. Instead of using more or less mechanical methods, he relied on his extraordinary visual memory to create his paintings using simple but reliable sketches taken in situ. Thus he painted panoramas of Paris, Rome, Naples, London and even Jerusalem or Athens, with assistants including Daguerre and Jean Prévost.

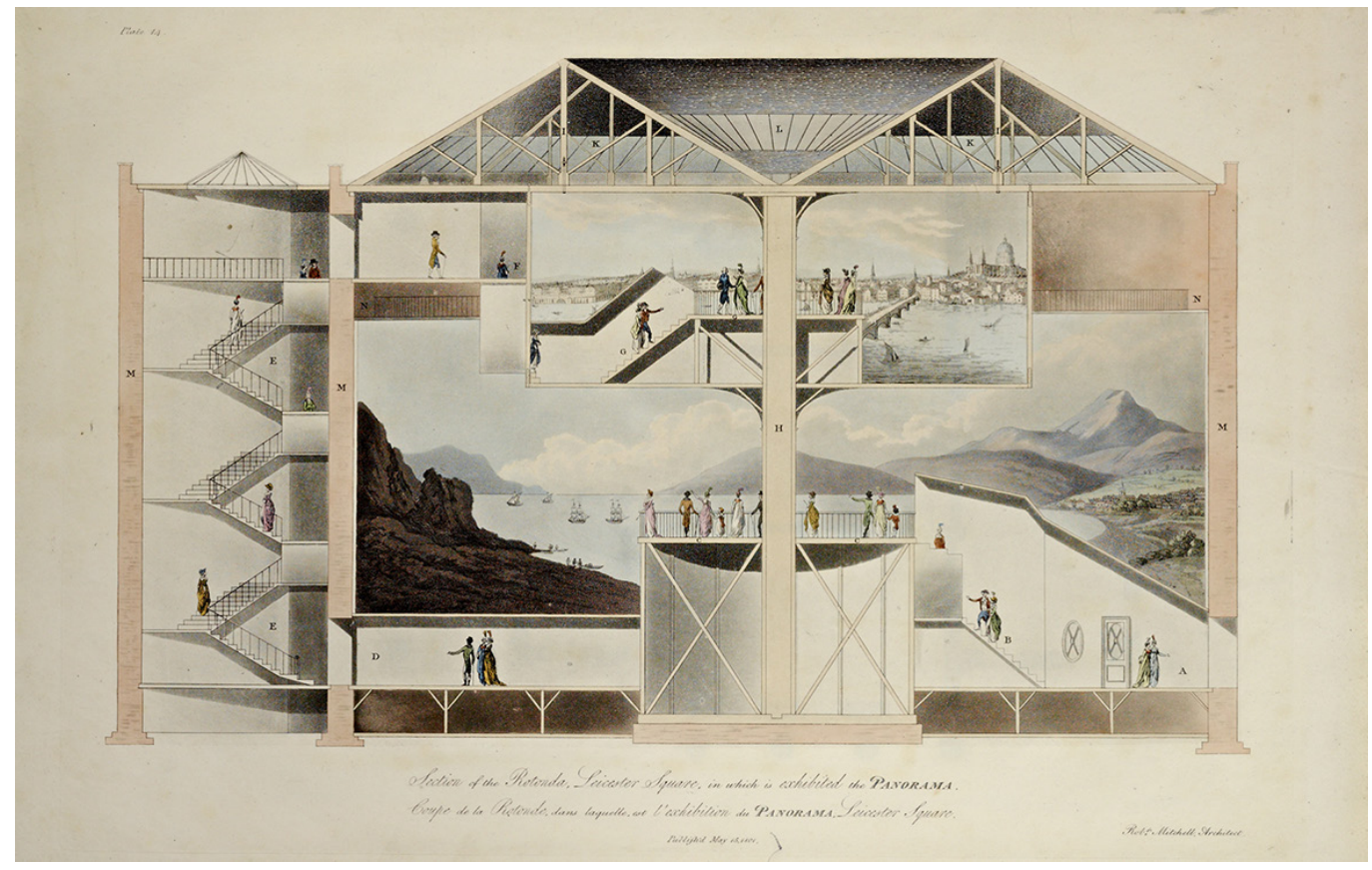


Fig. 5. H.W. Mesdag (1881). Panorama van Scheveningen. Museum Panorama Mesdag. Retrieved from https:// en.wikipedia.org/wiki/ File:Panorama_mesdas.

Fig. 6. Scientific American (1886). Photographing the field [The Cyclorama 1886, p. 296].
In Holland is the oldest surviving panorama, in what was once a small fishing village and now is a district of The Hague, Scheveningen, and dates from 188I. It can still be admired in its original location, the Mesdag museum of this town, dedicated to its author Hendrik Willem Mesdag, born in 1831. It measures 120 meters in circumference and over 14 meters in height, with a diameter of 40 meters [6], and was painted not only with the help of previous sketches but even photographs, which was then a major novelty (fig. 5). According to the official website of the museum, Vincent van Gogh was one of the guests at the opening and commented that it had only one defect: it is perfect!

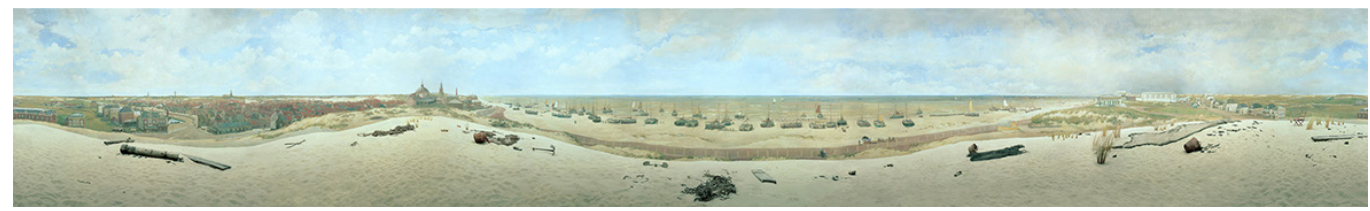

The cyclorama craze also led to the proliferation of buildings constructed with the specific or primary purpose of exhibiting this new form of representation of reality. In these constructions signed by architects, the promoter, who was often the author of the panoramas, had a fundamental role in their design. Robert Mitchell himself, the architect of the Rotunda, described Barker's idea in this way: "The Rotunda is divided into two compartments, which are concentric circles: this contrivance gives a double exhibition, by presenting for view two distinct pictures, an invention that happily has produced the most beneficial effects, not merely in pecuniary advantage, but in having at all times a picture to exhibit whilst the other is painting [...]. As the circle of the upper picture is much less than the under, an advantage is attained, that the under picture without interruption can occupy, if requisite, almost the whole height of the sides of the building. The forming of two exhibitions in this manner, in the same building, without interrupting or communicating with each other, is an original invention, without a precedent" [Mitchell I80 I, p. 8].

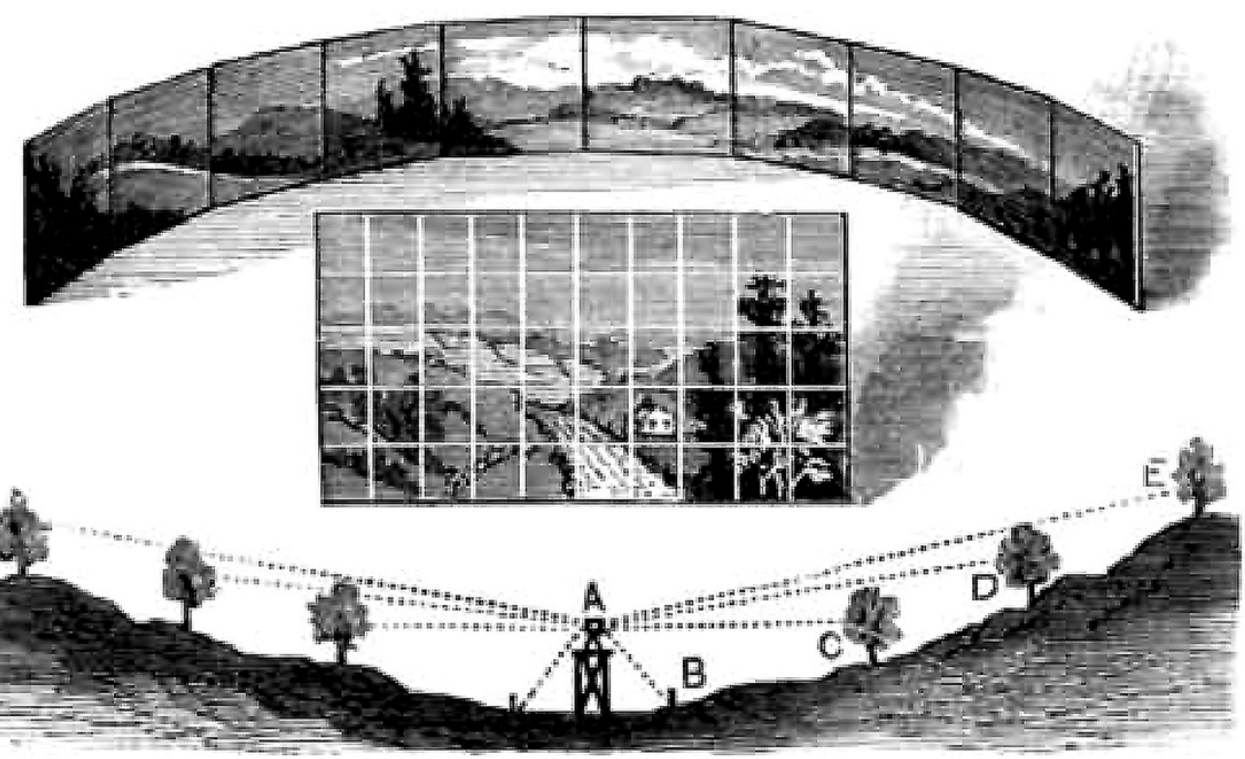

PHOTOGRAPHING THE FIELD. 
Thus we found that in order to accentuate the illusion of reality, the space between the panorama and the platform where the spectators were located was projected to place a simple three-dimensional set in the foreground. On this stage, elements such as figures, carts and other simpler elements are placed, as in the case of Gettysburg (fig. 7). In Mesdag, as the center of the panorama is on the shore of Scheveningen, this space is filled with sand from the beach itself.

In the United States, they took the concept of panorama a step further by introducing movement, i.e., rotating panoramas, which can be considered one of the antecedents of cinematography and constituted a true audiovisual spectacle, since the movement was accompanied by the music of a piano. It is attributed to the American John Banvard the creation of the first one in 1846, which he called Great Mobile Panorama of the Mississippi, as a result of two years of trips along the river. He later created other mobile panoramas such as those of the Nile and Jordan rivers, but none have been preserved [7]. As already noted, their background could be the landscapes on rolled paper of ancient China.

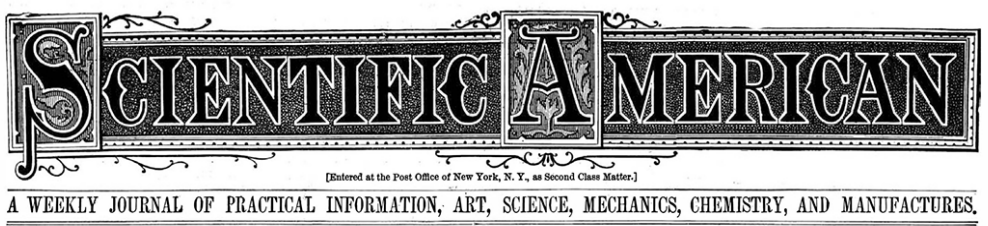

\begin{tabular}{|c|c|c|}
\hline 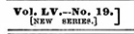 & NEW YORK, NOVEMBER 6, 1886. & 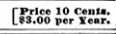 \\
\hline
\end{tabular}

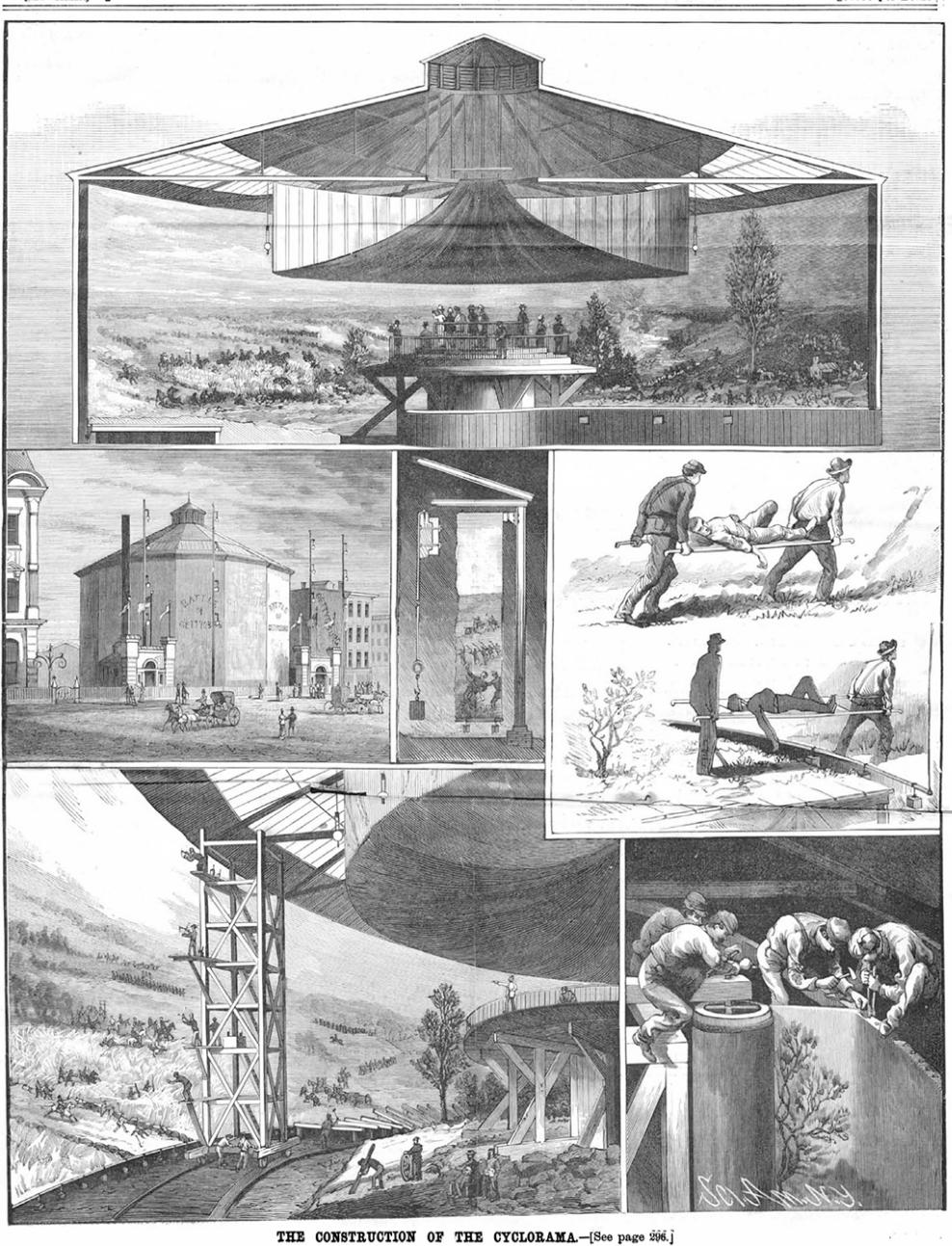




\section{The emergence of photography}

Photography was becoming increasingly important in the making of the panoramas but, given that for many years it was essentially monochromatic [8], even if photographs were used as the basis for the final drawings, the need to obtain the most realistic representation possible required a final color finish to achieve this, whether in oil or other pictorial techniques.

Thus, in I883, the French artist Paul Philippoteaux was hired to create a panorama, which he did with the help of numerous preparatory drawings and photographs commissioned from a professional, to commemorate an important battle of the American civil war, that one of Gettysburg, also known as the Pickett's Charge.

The diagram in figure 6 shows how the topographic base, i.e. the representation of the terrain, was made. With a series of photographs, it anticipates -and we could say that it surpasses- the current procedure for making $360^{\circ}$ panoramas that the virtual reality devices allow to observe individually without the need of displaying them in a circular building. This is how Scientific American described the process: "This was carried out in this particular cyclorama so as to secure almost absolute accuracy. The landscape is really an artistic transcript of photographic views of the field. The artist went personally to the field of Gettysburg. On it he selected a point of view, and a small stage of the height of the proposed audience stage was there erected. Around the stage a line of pickets was driven in a circle whose radius was forty feet-less than one-half the diameter of the cylindrical picture. The distance was measured from the stage as a center. From the top of the scaffold three identical series of ten photographic views each were taken" [The Cyclorama I886, p. 296].

Fig. 8. Richard Neutra, Robert Alexander (1963). Visitor Center-Cyclorama Building (destroyed) Gettysburg, Pennsylvania. Authis recreation (2020).

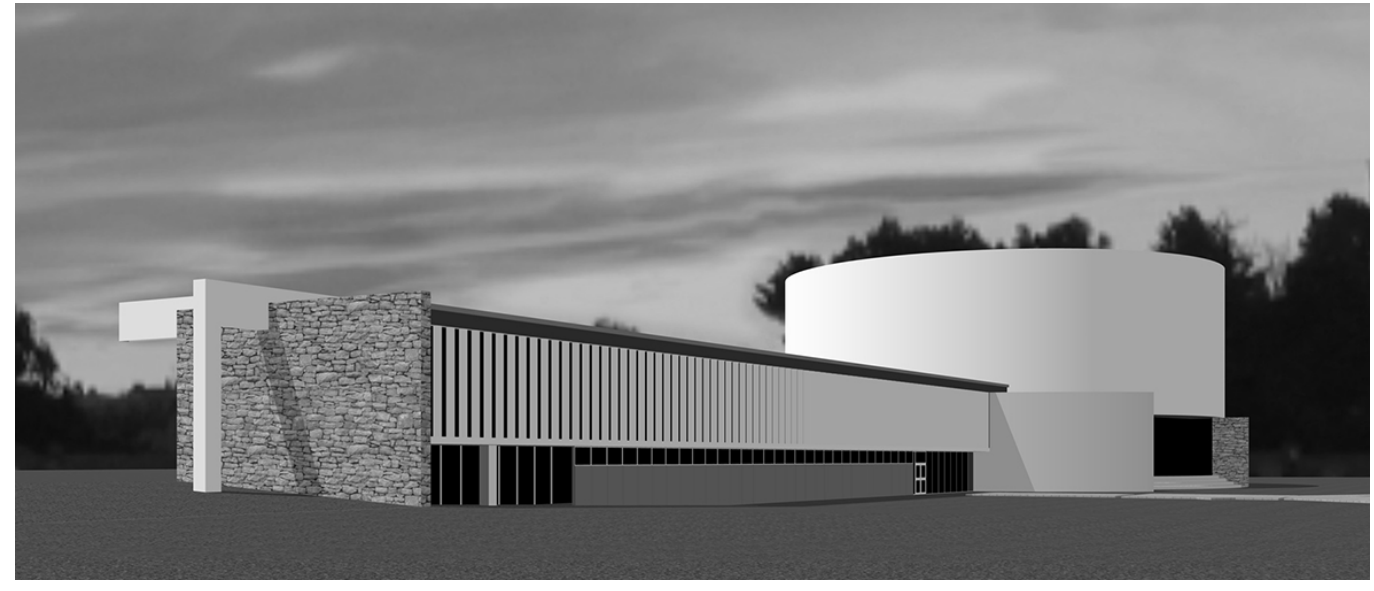

It was first exhibited in Chicago in 1883 with a foreground that included authentic relics of the battle, as well as fences, stone walls, roads or broken trees, constituting a resounding success for the public and critics, so they commissioned a second version that was exhibited in Boston in 1884. It was also briefly shown at City Hall Square, Brooklyn, New York (fig. 7). As an example of the detail employed, Scientific American wrote: "One curious instance is shown in the illustration. Two men are seen carrying a litter on which a wounded man rests. The more distant soldier is painted on the canvas. The litter is real, two of its handles passing through holes in the canvas. The figure resting on it is made of boards in the most curious segments, that seem to bear no relation to the final effect. The nearer bearer is cut out of a flat board" [The Cyclorama 1886, p. 296].

The American National Park Service acquired one of its versions in 1942 and later commissioned the project of the building to exhibit it to none other than the famous Austrian architect Richard Neutra. It was inaugurated in 1963, on the centenary of the battle and in that city. This jewel of modern architecture and one of the author's favorite works, was 
essentially a concrete and glass cylinder of more than 100 meters in circumference, which was completed with an assembly hall and other attached spaces [9] (fig. 8). Unfortunately, despite the worldwide campaign against it, it was demolished in March 2013 and the exhibition of the cyclorama is held in the museum at the Gettysburg National Military Park, which is located nearby.

From all the above it can be deduced, as Silvia Bordini points out, that the panorama,"Ben lungi dunque dall'essere una curiosita marginale, come potrebbe far supporre la sua scarsa fortuna in sede di studi di storia dell'arte, il Panorama si configura allo storico come un fenomeno estremamente complesso e articolato, e soprattutto largamente partecipe della mentalità coeva, paragonabile - con le dovute varianti - al cinema dell'età contemporanea" [Bordini 1984, p. 10].

\section{Deconstructing Virtual Reality}

We have seen how the creation of $360^{\circ}$ panoramas began with drawings taken from nature, in principle with the help of auxiliary instruments to situate the different points of view, as Barker, Prévost or Banvard did. Then, with the rapid evolution of photography, it became a complementary tool for their realization, as in the case of Mesdag, and even fundamental, as in the case of Philippoteaux. But ultimately, the final works were painted on canvas, usually in oil.

Fig. 9. Perspective elevation of the apse area of the church of the monastery of San Xoán de Poio, Pontevedra, Spain (photo by the author, 2019).

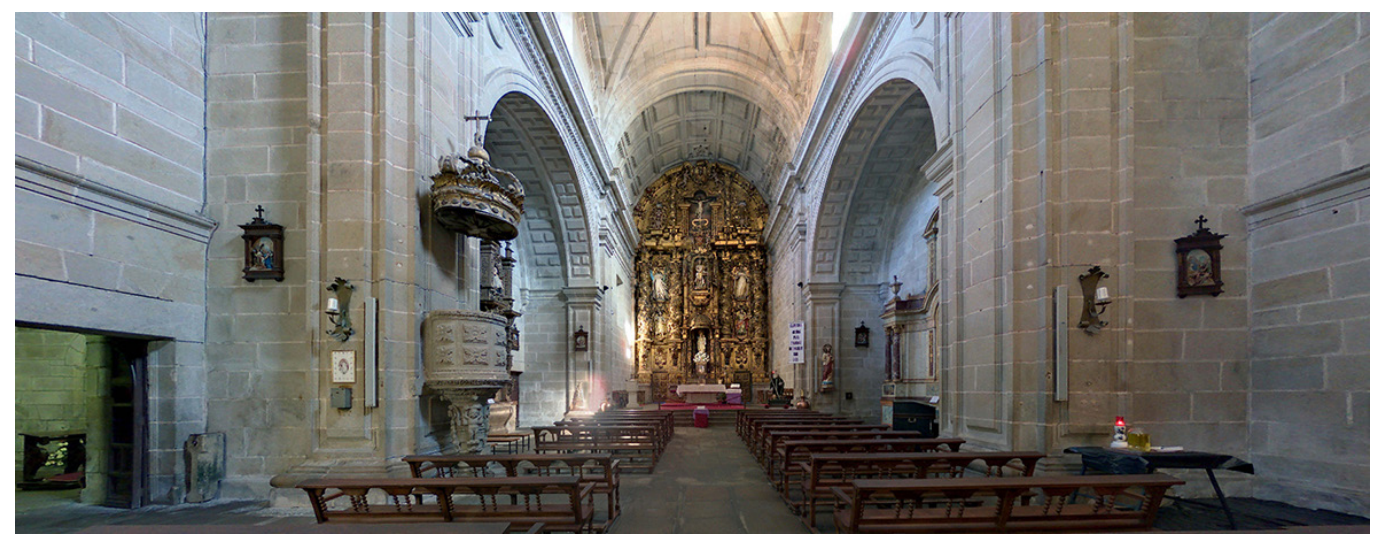

Fig. 10. Organs and coffered ceiling of the low choir of the church of the monastery of San Martín Pinario in Santiago de Compostela. On the right, the main bifronted altarpiece

the church (photo by the author, 2019).

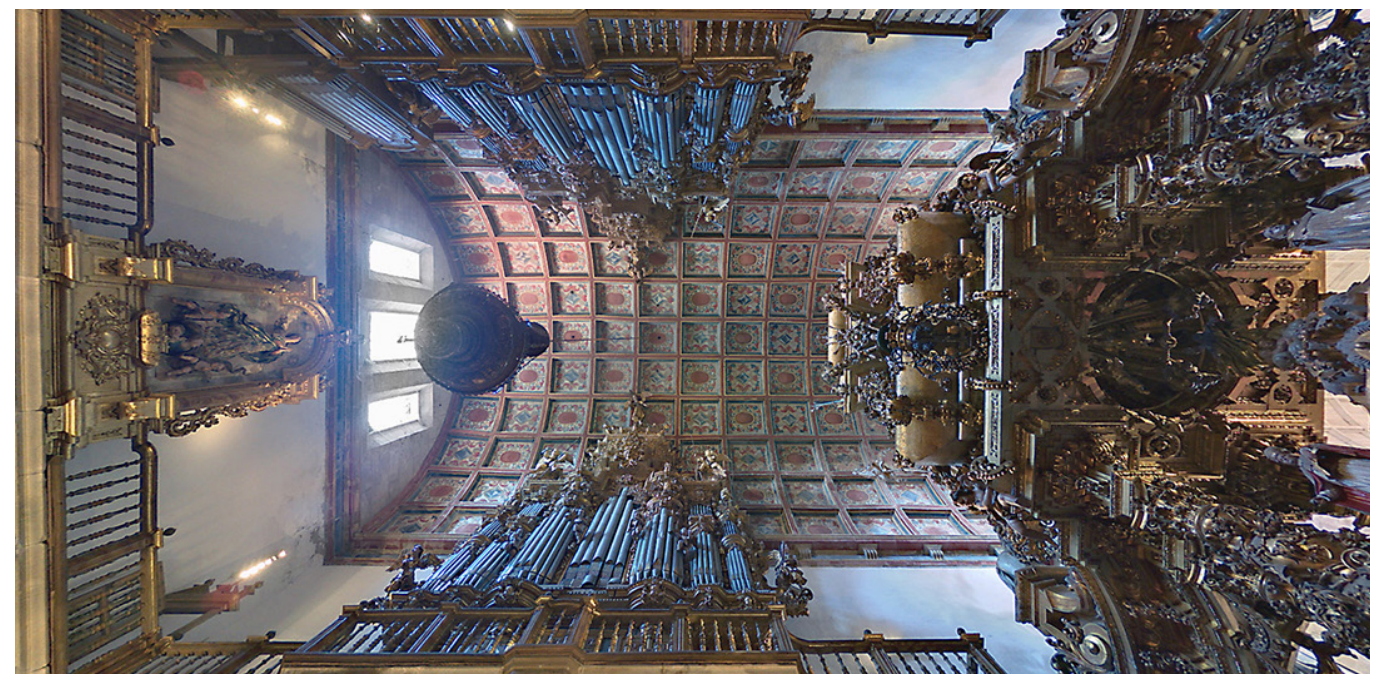


Panoramas as a public spectacle went into decline with the development of the cinematograph. But photography continued to evolve and when it was joined with computers it made possible the adequate fusion of the different partial images and, later, the possibility of obtaining a panorama -both cylindrical and spherical- directly by means of special cameras, called 'panoramic', provided with a minimum of two lenses and with the possibility of obtaining both photographs and videos [10]. With the glasses or stereoscopic viewfinders and other VR devices it is possible to take a step further the illusion of reality that so dazzled the first spectators of the 18th and 19th centuries.

In this work it is highlighted that it is possible, from the photographs taken with $360^{\circ}$ panoramic cameras, to practice the opposite procedure to the one that always characterized the traditional panoramas. That is, once a cylindrical or spherical panorama is obtained, partial screen captures can be made equivalent to photographs with lenses of the focal point of interest, whose definition will obviously depend on that of the panoramic camera used and the screen resolution of the computer employed for the capture. It would therefore be a kind of reverse graphic engineering. Obviously, this approach does not make as much sense with panoramas generated by merging several or many photographs with a smaller visual angle [II].
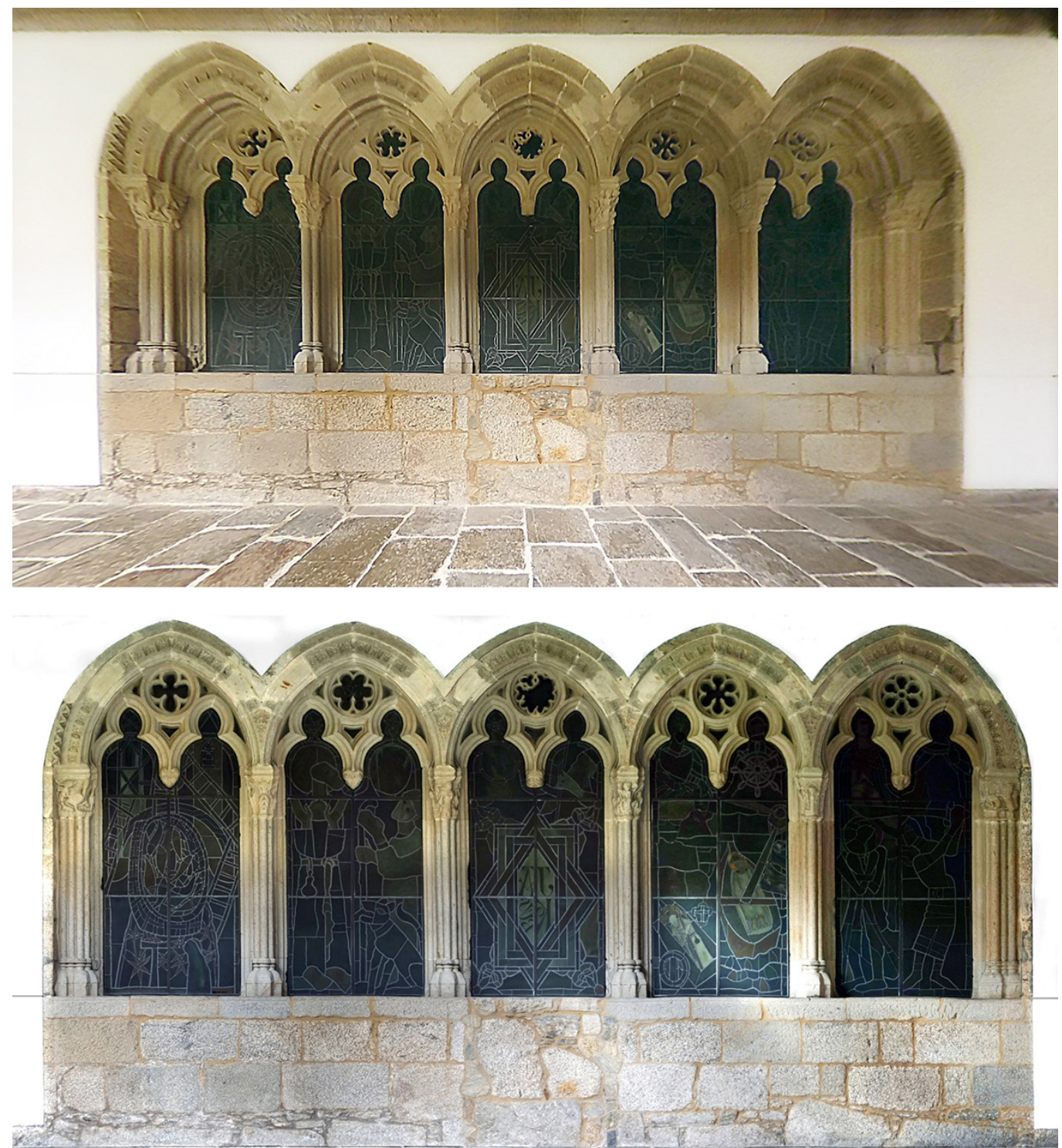
For example, the image in figure 9 is equivalent to an ultra wide-angle type photo (full frame lens $12 \mathrm{~mm}$ or less), taken as a $130^{\circ}$ screen shot of a $360^{\circ}$ spherical panorama photograph. In other words, the original panoramic photo has allowed us to obtain a partial view of the church, among the infinite number of possible ones, as if we had selected one among the numerous other virtual lenses available.

Figure 10 shows an unconventional view of the ceiling of the lower choir of the church of the Benedictine monastery of San Martín Pinario in Santiago de Compostela. It is also equivalent to an ultra wide-angle photograph although, like the previous one, it is a screenshot from a $360^{\circ}$ panorama. In other words, the a posteriori analysis of a single panoramic photograph allows us to obtain different images that can even replace, depending on the purpose of the work, the original panorama. It should be added that taking images of this type with conventional cameras, as complementary material for the graphic description of a room like this, would be much more complex and expensive. However, it should be noted that other factors need to be taken into account when using these 'virtual lenses', such as the distance between the motif and the panoramic camera. Figure II, above, shows a screen shot from a $360^{\circ}$ spherical panorama photograph. Since the Gothic arcade of the image is located in a gallery in the cloister of the convent of San Francisco de Santiago de Compostela, its narrowness means that the necessary visual angle of the image must be approximately $150^{\circ}$, which would be equivalent to an ultra wide-angle lens. But, despite the fact the capture does not show barrel-type deformations, the relative widths of the lateral jambs of the arch -although geometrically correct in linear perspective- seem deformed. This can be compared with the bottom image, an orthographic view of the three-dimensional model of the arcade made photogrammetrically. It is clear that if we lower the angle of vision we can obtain standard 'partial photographs' $\left(25^{\circ}-50^{\circ}\right)$ or wide-angle photographs $\left(60^{\circ}-100^{\circ}\right)$ like the one in figure 12 .

Fig. 12. Detail, from a $360^{\circ}$ spherical panorama of the cloister of the monastery of San Salvador de Lourenzá, Lugo, Spain (photo by the author 2019).

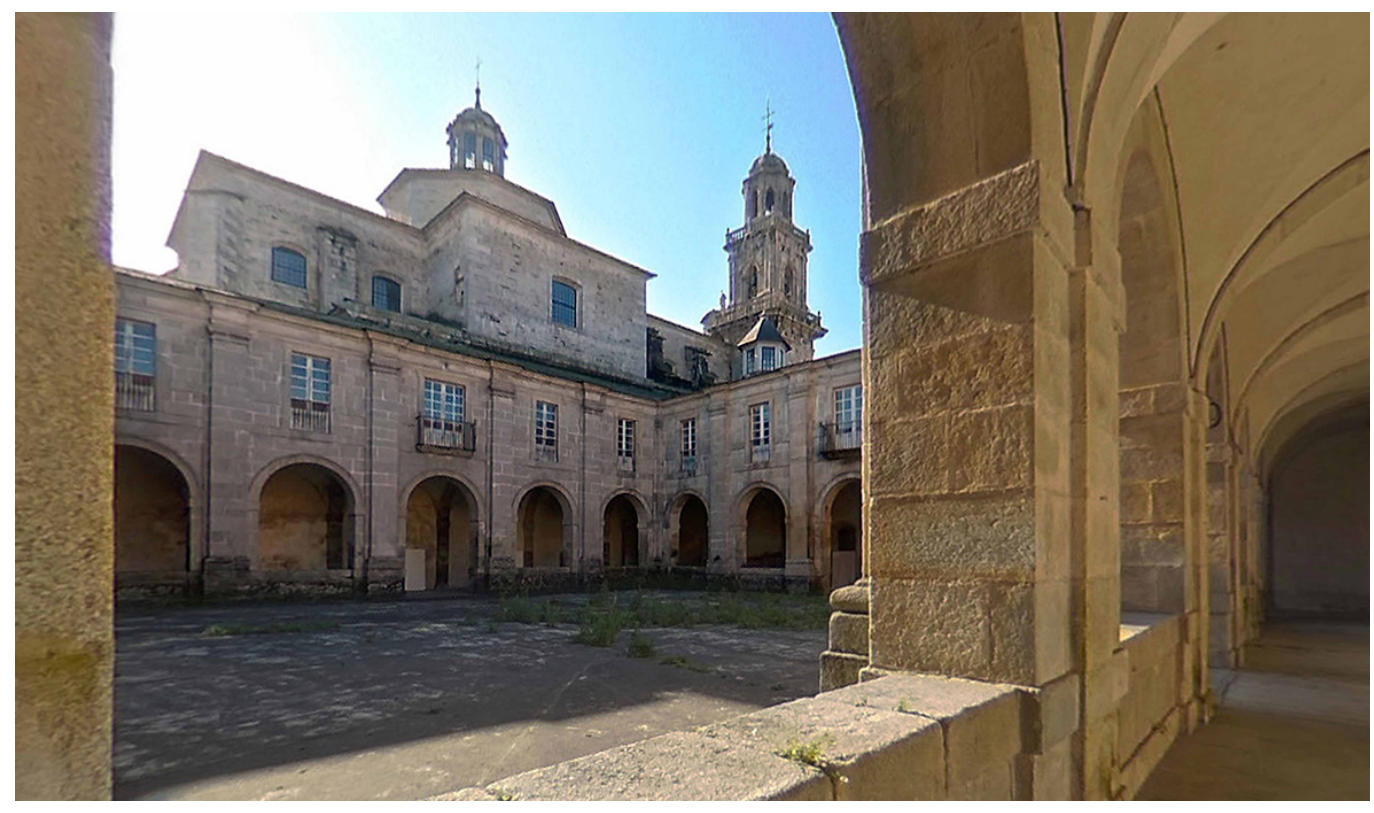

\section{Conclusions}

Finally, the main conclusion that can be drawn from this proposal is that the procedure described, in addition to providing economic advantages in terms of the photographic material needed, gives us the opportunity to take new shots that were not considered at the time, as well as the ability to explore a place from infinite positions. This is because the analysis of real space is governed by the laws of physics, which limit the movement of our bodies, while in the virtual worlds of our panoramas, our eyes can fly. In this way, sight can develop its full potential, that "specific power to distinguish or catch single space's views in few moments" of Fatta's speech. 
All this without entering into the range of expressive possibilities that this technique opens up to audiovisual creation, since panorama animation allows us to manipulate and deform digital space with great ease. It could thus serve a variety of artistic or narrative interests, as the great masters of German expressionism, such as Murnau or Fritz Lang, did in their day with the analogical media at their disposal. It is very suggestive to imagine what any of them could have created with the current technologies.

\section{Notes}

[I]Work partially related to the State R\&D Program for the promotion of scientific and technical research of excellence 2016 , of the Spanish State Research Agency: History of art, innovation and new technologies. Galician monastic and conventual heritage. From the reform of the Catholic Monarchs to Exclaustration. See: < http://arsmonasticorum.org/>.

[2] Oxford Advanced American Dictionary online: <https://www.oxfordlearnersdictionaries.com>.

[3] Available at: <https://www.comuseum.com/painting/masters/fan-kuan/>.

[4] Available at: < https://www.npm.gov.tw/en/Article.aspx?sNo=04006295>

[5] Sir Joshua Reynolds later rectified, praising his work.

[6] Data from the Mesdag Museum: <https://www.panorama-mesdag.nl/>.

[7] See: <http://medioevoaneoclasico.blogspot.com/201 I/05/john-banvard-curiosidades-esteticas.html>.

[8] The first photographic procedure was Niépce's heliographic one around I824, although the oldest preserved photograph is the famous View from the window in Le Gras, ca. 1826-1827. We will have to wait until 1839 for the commercialization of the daguerreotype and, almost simultaneously, of Talbot's calotype.

[9] I would like to thank the staff of the Library of the Higher Technical University College of Architecture, University of A Coruña, Spain, for the graphic documentation provided on this work by Neutra.

[I0] These cameras can be only a double lens that uses the smartphone as processor, like the Huawei 360 Panoramic VR Camera, with a price between 50 and 100 euros or other similar ones. Obviously, other pan cameras such as the Ricoh Theta offer higher quality, but are somewhat more expensive. Then there are the semi-professional ones, such as the Panono, with 36 sensors, as well as others that are already professional.

[I I] In this work, the expression 'visual angle' always refers to the horizontal angle.

\section{References}

Bordini Silvia ( 1984). Storia del panorama. La visione totale nella pittura del XIX secolo. Roma: Officina Edizioni.

Fatta Francesca (20 I 6). Science and art between time and place: six points of view. In XY, year I, n. I, pp. 44-57.

Knobler Nathan (1980). The Visual Dialogue. New York: Holt, Rinehart, and Winston.

Mitchell Robert (I80I). Plans and views in perspective, with descriptions of buildings erected in England and Scotland. London: Wilson \& Co. Retrieved. Available at: <https://archive.org/details/gri_33125008065258/page/n65/mode/2up.

Stickland Walter G. (19|3). A Dictionary of Irish Artists. Vol. I. Dublin: A to K. Mansel \& Company, Limited. Available at: <http:// www.askaboutireland.ie/aai-files/assets/ebooks/ebooks-20 I I/A-Dictionary-Of-Irish-Artists/A\%20DICTIONARY\%200F\%20 IRISH\%20ARTISTS_STRICKLAND_I (A-K).pdf>.

"The Cyclorama" ( 1 886). In Scientific American, Vol. LV.-No. 19. November 6, I886, pp. 287-296.

Corner George Richard (1857). The Panorama: with memories of its inventor, Robert Barker, and his son, the late Henry Aston Barker. In Art Journal, vol. III. January I, pp. 46-47.

Zöllner Frank, Nathan Johannes (2003). Leonardo da Vinci, I452- I 1 9: the complete paintings and drawings. Köln: Taschen.

\section{Author}

José Antonio Franco Taboada, Universidade da Coruña, jafranco@udc.es

To cite this chapter: Taboada José Antonio Franco (2020). The search for the 'view of the totality': from the first panoramic landscapes to virtual reality. In Arena A., Arena M., Brandolino R.G., Colistra D., Ginex G., Mediati D., Nucifora S., Raffa P. (2020). Connettere. Un disegno per annodare e tessere. Atti del $42^{\circ}$ Convegno Internazionale dei Docenti delle Discipline della Rappresentazione/Connecting. Drawing for weaving relationships. Proceedings of the 42th International Conference of Representation Disciplines Teachers. Milano: FrancoAngeli, pp. 3800-38I0. 